Journal of

Language and

JLD (PRINT) ISSN 2397-2637

Discrimination

JLD (ONLINE) ISSN 2397-2645

Review

\title{
Linguistic Discrimination in U.S. Higher Education: Power, Prejudice, Impacts and Remedies \\ By G. Clements and M. J. Petray (2021) \\ New York: Routledge, 224 pp.
}

Reviewed by Weijia Shan and Zhenjun Lin

KEYWORDS: LINGUISTIC DISCRIMINATION; HIGHER EDUCATION; POWER; REMEDIES

Who do you sound like? Have you ever encountered language discrimination on campus? 'Linguistic Discrimination in U.S. Higher Education: Power, Prejudice, Impacts and Remedies' is a good choice for sociolinguistic beginners who are interested in linguistic discrimination (LD) and researchers in sociolinguistics and education. It provides a selection of essays relating to LD studies in U.S. Higher Education, which aims at increasing linguistic awareness in LD, discussing the appropriate varieties on campus, impacts of LD, and finding the solutions to LD.

This book comprises 11 chapters. Chapter 1, written by the editor Gaillynn Clements, serves as an introduction for the whole book. The background information of LD on campus is fully exposed. The introduction includes what is LD, why does LD appear and what role does college play in LD. Specifically, first, Clements notes the basic concept of linguistic discrimination. Language conveys meaning at first and then is connected with some stereotypical characteristics. Under standard language ideology, the students and staff on campus are judged by these stereotypes to some extent. Then, Clements illustrates the origin of standard language ideology (SLI). Additionally, an overview of the power of institution in LD behind

$\overline{\text { Affiliation }}$

Weijia Shan: School of Foreign Languages, Northeast Normal University email:danwj032@nenu.edu.cn

Zhenjun Lin: School of English and International Studies, Beijing Foreign University email: linzj@bfsu.edu.cn 
students and staff on campus gives us a full vision of LD in higher education. Finally, the guide for chapters is given.

Chapter 2-10 are concrete essays selected by the editors, which can be divided into six themes according to the content. Providing sufficient linguistic material, these themes cover a lot of ground about LD on U.S. campuses for the readers. However, the drawback is that there is no clear division for each theme in the table of contents. A clear guide for the themes would be more helpful in getting to the required content quickly for the readers. Though a clear outline of the book is given at the end of the opening article, a guide in the table of contents would make the book more reader-friendly.

Chapters 2-4 illustrate the theme on the assessments of students' writing materials. This theme is achieved by highlighting the LD existing in written assessments and giving suggestions for instructors and students to respect linguistic diversity. Melinda Reichelt's essay in Chapter 2 concentrates on ESL students' writing. Starting from a thorough literature review of ESL writing on linguistic error preoccupation and how instructors react to ESL students' writing, Melinda gives suggestions against LD in these students. Ho'omana Nathan Horton's essay in Chapter 3 argues the existing standard language ideology in the University English Classroom by investigating whether certain morphosyntactic properties of AfricanAmerican English impact students' scores. Also, the views of instructors in the features belonging to any stigmatised variety of English are analysed to be unjust. Then, the suggestions for raising the awareness of this kind of LD and valuing linguistic diversity are given. Sonja Launspach's essay in Chapter 4 talks about the fact that students' writing varieties are still limited even though writing instructors have enough linguistic training and awareness of language diversity. This essay gives a detailed demonstration on the deep reason, the unequal power, behind this phenomenon. In all these three chapters, it is believed that instructors play an important role in eliminating impacts of LD. The instructors and educators should recognise LD in daily teaching activities, take measures to reduce linguistic bias and respect the diversified expressions of students.

Katherine Yaw and Okim Kang's essay in Chapter 5 focuses on another theme dealing with international teaching assistants (ITAs). ITAs are essential in the U.S. higher education system, but they still face the problems of LD. This essay addresses this LD phenomenon towards ITAs on U.S. campuses, and 'intergroup contact' is initiated to reduce the negative attitude towards these groups of people in higher education. Actually, this chapter is abrupt to be treated as a single theme to some extent. More

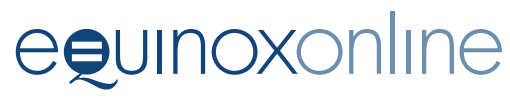


essays on this topic could be added, or divide this essay into the next theme will be more appropriate, considering the organisation of the book.

The next section contains Chapters 6-8, concerning the LD towards particular groups of people during the admissions/hiring stage and learning stage on campuses. Usually, these groups use or study the language or dialect of a minority group. Jon Henner and Octavian Robinson's essay in Chapter 6 figures out the linguistic discrimination towards people who use or study sign language in academic areas. They call for an equal status of sign language and the just treatment for its users and researchers in academic fields. Through the careful semi-structured interviews of women and men faculty members of different colleges and departments and a series of qualitative analysis, Caroline Myrick's essay in Chapter 7 reveals the fact that there are language and gender discriminations in colleges. These biases create inequality in various situations especially for women faculty members in higher education system, such as in the classroom, faculty meetings and hiring process. This essay discusses how women faculty members follow or resist these stereotypes and expectations derived from inequality, as well. Also, Christopher Scott's essay in Chapter 8 discusses the LD in terms of Lumbee dialect through a well-designed semi-structured interview towards 11 full-time college students. This essay addresses that speaking the dialect has a negative effect in both academic achievements and identity development. There is a trend of assimilation towards standard language dominated by White institutions, but there are still some properties remaining in their language, which represent the uniqueness of Lumbee people. The more minority students participate in social institutions, the more elimination of their linguistic uniqueness will take place.

All of these three chapters elucidate the fact that LD is quite pervasive in campus life and exerts negative effects on the academic career for both higher education faculty and students. These essays give the readers a wide view of LD in universities. At the same time, target readers would have great empathy with the essays for their identities under the higher education system.

The last theme exemplified in Chapter 9 and Chapter 10 shifts to the universities' reactions to LD and their initiatives to reduce the negative effects of LD in order to embrace diversity in universities. Walt Wolfram and Stephany Dunstan's essay in Chapter 9 stresses that linguists and sociolinguists should not fight against LD in higher education only by expressing their ideas in linguistic courses but take practical actions for the university. The 'campus-infusion' model and program for dealing with LD problems at North Carolina State University demonstrate this. Christina Higgins' essay

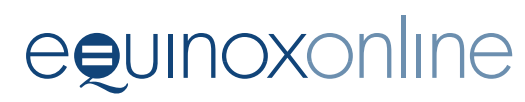


in Chapter 10 gives accounts of several initiatives that University of Hawaii $i$ at Ma-noa (UHM) applies to support the equal right of Pidgin speakers in the university. A detailed instruction of Pidgin history and the situations of Pidgin at UHM are given. Moreover, further suggestions in Pidgin advocacy are listed. Chapters 9 and 10 both stress the role of universities in dealing with LD. Having an awareness of LD and taking actions at university level or an even higher one, the initiatives aiming at reducing negative effects of LD can contribute to the language diversity and language equality in higher education system more deeply and profoundly.

Finally, a concluding essay is given by the two editors, Marnie Jo Petray and Gaillynn Clements, in Chapter 11. Above all, very fine-grained explanations of fundamental concepts for understanding and dismantling linguistic discrimination are provided, which provides a lot of help for the beginners in this area. Also, students will get a clear guide for the basic concepts they are required to know in the courses related to LD. Then they offer several remedies to LD. We need to increase linguistic awareness to support speaker identity. It is the college and university community members that will be the pioneers against LD. Authorities should give agency to people, making them powerful in language choice. Furthermore, every individual also has the responsibility to make a change in LD.

Language belongs to everyone, but LD still exists in the campus environment. People using minor language forms or dialects often face threats to their academic achievements or career advancement. Despite a few disadvantages in content arrangement, this book is still a good choice. The charm of this book lies in three aspects. First, it offers fine-grained introductions on basic concepts of LD, multiple study perspectives and sufficient linguistic data of this topic, which is a model for the course books in terms of academic contribution. Second, it contributes to the linguistic equality in universities from the perspective of the university education. Third, full of humanistic concern, this book shows the sociolinguists' emotional care towards the students, staff and faculty suffering the discriminations under the higher education system, which is a very critical value orientation for sociolinguistic study. Just as Marnie Jo Petray and Gaillynn Clements say:

\footnotetext{
'We all have the right to query, discuss, debate and advocate for changes we see as necessary to increase agency and to support students, staff and faculty identities and experiences on campuses...' (p. 199)
} 